\title{
Is there a Greater Risk in the Use of Hormones Nowadays?
}

\section{Huang Wei Ling*}

Infectious Diseases, General Practice, Nutrition, Acupuncture and Pain Management, Medical Acupuncture and Pain Management Clinic, Franca, São Paulo, Brazil

*Corresponding Author: Huang Wei Ling, Infectious Diseases, General Practice, Nutrition, Acupuncture and Pain Management, Medical Acupuncture and Pain Management Clinic, Franca, São Paulo, Brazil.

The implantation of the Flexner report in almost all the continents in 1913, brought the modernization of medicine in all areas related to the diagnosis and treatment of the most diverse pathologies, but at the same time, many of its negative effects we can see in our today's patient. Also, the modernization of the devices used in the communication with the implementation of $5 \mathrm{G}$ technology brought changes that few studies have shown, because these changes are subtle and not noticeable to the naked eye $[1,2]$.

In the article written by Hardell and Carberg (2020) entitled Health risks from radiofrequency radiation, including $5 G$, should be assessed by experts with no conflicts of interest, the authors are saying that most studies done in this field to see if the electromagnetic waves could harm the health of the human being are saying that this kinds of waves do not harm health but usually there are cartels of people who are monopolizing this committees reinforcing the no-risk paradigm and in according to Hardell, should be qualify as scientific misconduct [2].

These effects are not visible to the naked eye, and in such a subtle way and without realizing it, the levels of diabetes, cancer, myocardial infarction and thrombosis are increasing, in addition to the increase in suicide among many other pathologies such as depression, anxiety, insomnia, obesity, etc. [3-10].

The lack of holistic vision of the human being and the lack of understanding that all the matter existing in our universe is composed of energy, very well explained in the book of the physicist Capra (1975) whose title is The Tao of Physics, in which the author compares the duality existing between the two kinds of medicines (Western and Chinese medicine) [11].
Received: June 02, 2021

Published: July 09, 2021

(C) All rights are reserved by Huang Wei Ling.
This duality could not exist, since we are talking about the same thing as human beings, which are composed in a physical (material), emotional and spiritual way [11].

The so-called scientific thinking nowadays, has been very criticized by the patients themselves, who receive this type of treatment, which before was for one thing and after starts to take other remedies to remedy the side effects generated by the first one.

As far as women's health is concerned, the hormonal and reproductive cycle is not only governed simply by the hormonal aspect, very well described in the gynecology book Obstetrics and gynecology in Chinese medicine, written by Giovanni Maciocia (1998) but behind these circles are the energies that are often not visible with the naked eye [12].

To exemplify this, the author compares as the very cellular device that almost every inhabitant of this planet has at least one. People carry these devices daily for the purpose of maintaining communication and their chores in daily work and when these devices are not charged daily, simply they do not work.

When a woman's body becomes sick, or when she gets fat or loses her sexual appetite or enters an aging process or when she has difficulty getting pregnant, all of this can be a sign that her internal energy is in disequilibrium or deficient in energy and sometimes laboratory tests are performed to check for the presence of any abnormality, and often, the doctor cannot find anything to justify such symptom. As the author showed in her article What are the sources of fibromyalgia and how to treat it without using anti-inflammatory or anti-depressant drugs?, she is explaining in this article that patients with fibromyalgia have alterations in the energy level (Blood 
deficiency) but this alteration does not appear in the laboratory exams and this kinds of patients usually is treated as they have some emotional problems but the fact is that they have alterations in the energy level, that is not seeing by the naked eyes [13].

The author says that all this has as a background the imbalances of the internal energy that are behind the hormonal imbalances, which are controlling the functioning of all the glands of the organism through the chakras, much rejected nowadays in Western medicine because they say that this kind of medicine is classified as no scientific. However, this lack of holistic vision, considering the energy part leading to the formation of the disease, very well described in several publications by the author, has generated many problems or delayed diagnosis of patients in general [3-10].

In the article Chakras' and energy deficiencies in the genesis of breast cancer, written by the author (2021) for example, the author shows the other standpoint on the formation of breast cancer from the energy point of view, where nowadays diseases are only treated in their symptom, where the breast cancer is treated by itself, but energy changes are never evaluated, due to so-called "scientific" medicine where you see the human being only through an angle, cut in half, not fully understanding that all disease is generated by an energy imbalance, which is not normally visible to the naked eye [3-10].

These alterations are capable of generating diseases as in the article published by the author (2020) Energies and Chakras Replenishment in Prevention and Treatment of Patients with Atypical Pap Cells Exam, where the author describes how to treat patients with pre malignant alteration in the examination of pap smear only rebalancing the internal energy by changing the patient's diet, performing some acupuncture sessions and filling the chakras' energies centers energy using highly diluted medications according to the theory created by her (2020) entitled Constitutional Homeopathy of the Five Elements Based on Traditional Chinese Medicine. In another article written by the author (2021) entitled Energies Alterations and Chakras' Energies Deficiencies as One Cause of Abnormal Uterine Bleeding in Women, where she explains that these patients who have abnormal uterine bleeding, have a deficiency in the energy of the chakras' energy centers, which are not visible to the naked eye, but must be considered because the being human is made of energy, before becoming a matter [4-6].

The use of hormones nowadays must be carried out with great caution because in a study carried out by the author studying 1000 patients in her clinic in Brazil, during the period from 2015 to 2020, she demonstrates that more than 90 percent of her patients do not have energy in the chakras' energy centers, thus they are having reduced immunity and predisposition to the formation of all diseases nowadays including COVID-19, explaining why not only patients with comorbidities, but children, adolescents, young adults are getting sick even without having any pathology base. The use of hormones in patients with weak energy in the chakras' energy centers can reduce even more he vital energy, very well explained in the Arndt Shultz Law, originally formulated in 1888, by two German researchers. In this law, they are saying that the use of highly concentrated medications can reduce even more the vital energy (hormones are considered highly concentrated medications) and can cause other complications such as neurologic diseases and others that the author will present in the International Conference on Neurology and Neurosurgery in Singapore in December 2021 $[10,14]$.

In another study presented by the author in two webinars, the first in the 13th International Summit on Gynaecology, Obstretrics and Women's Health and in the second Webinar on Cancer Research, both on May 2021, whose title was Malignant Ovary Tumor Secondary to Chronic Use of Hormones to Treat Acne, the author is explaining in this study that the patient reported in this study used 10 years of hormone and evolved with malignant cancer formation in the right ovary. This patient presented a depletion of energy in all chakras' energy centers in the radiesthesia procedure, which worsened with the chronic use of hormones, very well explained in the Arndt Shultz Law [14].

Our vital energy is able to eliminate the malignant cells that normally our body produces daily, explained by the author (2020) in an article The Importance of Treating Energy Imbalances and Chakras Replenishment for Prevention and Treatment of Cancer. With the reduction of vital energy, using any kind of highly concentrated medications, the patient's body weakens and lost the ability to eliminate these cells, ending up with the formation of cancer [7].

In another article written by the author (2020) entitled Chakra's Energy Deficiency as One of the Cause of Menopause Symptoms in Women, she is explaining that women with menopause symptoms have chakras' energy centers deficient in energy and the treatment replenishing these chakras' using highly diluted medications according to the theory Constitutional Homeopathy of the Five Elements Based on Traditional Chinese Medicine is a very important tool in the treatment of all these patients instead of using hor- 
mones (that could increase the formation of cancer). Using this kind of treatment, replenishing the chakras' energy centers, the chance to acquire cancer will reduce and the symptoms of menopause will be treated $[6,8]$.

So, in the face of the chaos the world is in, for these few lines the author come to say that we need to understand how is the beginning of the process of formation of diseases at energy level and for this end, we need to reevaluate the medical model that is implanted today, which already it no longer meets the needs of women in general due to the change in their energy pattern. The maintenance of this current medical system, will only lead to the formation of more diseases due to the type of medication used today. According to the publication Is the Population in the World the Same as in the Past? the author states that the type of medication we should prescribe will depend on the type of population we have today. And in her (2021) article entitled Energy Alterations and Chakras' Energy Deficiencies and Propensity to SARS-CoV-2 Infection, she is demonstrating that the majority of the population that she is attending ( $>90 \%)$ were in the lowest level of energy, very different as she compared to the patient in the past six or seven year ago. For this reason, the kind of medications that we can prescribe will depend on the type of the population we have nowadays and the use of highly concentrated medications, recommended in all Western medicine's medical schools would harm more the vital energy and lead to more formation of more diseases in the future or aggravate diseases that is installed in the patients' body $[9,10]$.

\section{Bibliography}

1. Flexner A., et al. "Medical education in the United States and Canada. From the Carnegie Foundation for the Advancement of Teaching, Bulletin Number Four, 1910". Bulletin of the World Health Organization 80.7 (2002): 594-602.

2. Hardell L and Carlberg M. "Health risks from radiofrequency radiation, including $5 \mathrm{G}$, should be assessed by experts with no conflicts of interest". Oncology Letter 20.4 (2020): 15.

3. Huang WL. "Chakras' and energy deficiencies in the genesis of breast cancer". Obstetrics and Gynecology International 12.2 (2021): 53-62.

4. Huang WL. "Energies Alterations and Chakras' Energies Deficiencies as One Cause of Abnormal Uterine Bleeding in Women". Journal of Womens Health Care and Management 2.1 (2021): 114.
5. Ling HW. "Energies and Chakras Replenishment in Prevention and Treatment of Patients with Atypical Pap Cells Exam". Journal of Womens Health Care and Management 1.2 (2020): 108.

6. Huang WL. "Constitutional homeopathy of five elements based on traditional Chinese medicine". Acta Scientific Microbiology 4 (2020): 57-69

7. Huang WL. The Importance of Treating Energy Imbalances and Chakras Replenishment for Prevention and Treatment of Cancer". Advances in Cancer Research and Clinical Imaging 3.1 (2020).

8. Huang WL. "Chakra's Energy Deficiency as One of the Cause of Menopause Symptoms in Women". Journal of Women's Health and Reproductive Medicine 4.3 (2020): 2.

9. Huang WL. "Is the Population in the World the Same as in the Past?". Acta Scientific Clinical Case Reports 2.6 (2021).

10. Huang Wei Ling. "Energy Alterations and Chakras' Energy Deficiencies and Propensity to SARS-CoV-2 Infection". Acta Scientific Microbiology 4.4 (2021): 167-196.

11. Capra Fritjof. The Tao Of Physics : an Exploration of the Parallels between Modern Physics and Eastern Mysticism. Berkeley: [New York]: Shambhala ; distributed in the U.S. by Random House (1975).

12. Maciocia G. "Obstetrics and Gynecology in Chinese Medicine". ROCA (1998).

13. Huang WL. "What are the Sources of Fibromyalgia and How to treat it Without Using Anti-Inflammatory or Anti-Depressant Drugs?". Journal of Gynecology and Obstetrics 2.2 (2019): 001009.

14. LEESER 0. "Support of homeopathy by the Arndt-Schulz law". National Center for Biotechnology Information 24.14 (1953): 417-421.

\section{Volume 3 Issue 8 August 2021} (C) All rights are reserved by Huang Wei Ling. 